\title{
Changes in Dpysl2 expression are associated with prenatally stressed rat offspring and susceptibility to schizophrenia in humans
}

\author{
HWAYOUNG LEE ${ }^{1}$, JAESOON JOO ${ }^{1}$, SEONG-SU NAH ${ }^{2}$, JONG WOO KIM ${ }^{3}$, HYUNG-KI KIM ${ }^{1}$, \\ JUN-TACK KWON ${ }^{1}$, HWA-YOUNG LEE ${ }^{4}$, YOUNG OCK KIM ${ }^{5}$ and HAK-JAE KIM ${ }^{1,6}$
}

\begin{abstract}
${ }^{1}$ Department of Clinical Pharmacology, ${ }^{2}$ Division of Rheumatology, Department of Internal Medicine, College of Medicine, Soonchunhyang University, Cheonan; ${ }^{3}$ Department of Neuropsychiatry, School of Medicine, Kyunghee University, Seoul;

${ }^{4}$ Department of Psychiatry, College of Medicine, Soonchunhyang University, Cheonan; ${ }^{5}$ Development of Ginseng and Medical Plants Research Institute, Rural Administration, Eumseong; ${ }^{6}$ Soonchunhyang Medical Research Institute, College of Medicine, Soonchunhyang University, Cheonan, Republic of Korea
\end{abstract}

Received August 22, 2014; Accepted March 26, 2015

DOI: $10.3892 / \mathrm{ijmm} .2015 .2161$

\begin{abstract}
Exposure to stress during critical periods of fetal brain development is an environmental risk factor for the development of schizophrenia in adult offspring. In the present study, a repeated-variable stress paradigm was applied to pregnant rats during the last week of gestation, which is analogous to the second trimester of brain development in humans. Behavioral and proteomic analyses were conducted in prenatally-stressed (PNS) adult offspring and non-stressed (NS) adult controls. In the behavioral tests, grooming behavior in the social interaction test, line-crossing behavior in the open field test, and swimming behavior in the forced swimming test were decreased in the PNS group. Western blot analysis and immunohistochemical analysis revealed that the expression of dihydropyrimidinase-like 2 (Dpysl2) or collapsin response mediator protein 2 (Crmp2) was downregulated in the prefrontal cortex and hippocampus of rats in the PNS group. Subsequently, single-nucleotide polymorphisms (SNPs) of the human dihydropyrimidinase-like 2 (DPYSL2) gene were analyzed in a population. Two functional SNPs (rs9886448 in the promoter region and rs2289593 in the exon region) were associated with susceptibility to schizophrenia. The present findings demonstrated that the downregulation of genes such as Dpysl2 and Dypsl3 in a rat model of prenatal stress may affect subsequent behavioral changes and that polymorphisms of the DPYSL2 gene in humans may be associated with the
\end{abstract}

Correspondence to: Professor Hak-Jae Kim, Department of Clinical Pharmacology, College of Medicine, Soonchunhyang University, 31 Soonchunyang 6-gil, Cheonan 330-721, Republic of Korea

E-mail: hak3962@sch.ac.kr

Key words: dihydropyrimidinase-like 2, social interaction, single nucleotide polymorphism, prenatal stress development of schizophrenia. Taken together with previous studies investigating the association between the DPYSL2 gene and schizophrenia, the present findings may contribute additional evidence regarding developmental theories of the pathophysiology of schizophrenia.

\section{Introduction}

Schizophrenia is a well-known psychiatric disorder with a developmental etiology that is associated with abnormal mental functions and behaviors, including delusions, hallucinations, disorganized thinking, and negative symptoms. Additionally, many patients exhibit concomitant mood symptoms, such as depression and anxiety, which may contribute to the $10 \%$ lifetime incidence of suicide in schizophrenic patients $(1,2)$. Prenatal stress (PNS) is among the most frequently reported environmental risk factors for the development of schizophrenia in adults (3-8), and the second trimester of pregnancy in humans seems to be the most vulnerable period for insults (8). Furthermore, a number of animal studies have shown that maternal exposure to stress during gestation elevates glucocorticoids and that this type of stress is associated with various biochemical, physiological, and behavioral changes in offspring, including reduced birth weight, cardiovascular and neuroendocrinological abnormalities, attentional dysfunction, enhanced anxiety-related behaviors, and cognitive deficits (9-18). In studies investigating this connection, pregnant female rats are usually exposed to stressful manipulations during the third week of pregnancy, which, in terms of neural development, is equivalent to the second trimester of human gestation (15-17).

Previous findings have demonstrated that PNS or maternal exposure to glucocorticoids may affect the responsivity of the hypothalamic-pituitary-adrenal (HPA) axis and can induce cognitive deficits in offspring $(10,16,17,19-22)$. Cognitive deficits that result from disrupted hippocampal anatomy and impaired function of the HPA axis are also typically observed in patients with schizophrenia $(23,24)$. In animal studies, PNS 
results in a reduced number of hippocampal synapses as well as fewer neurons in the brain (25). Moreover, the hippocampi of adolescent and adult male rats exposed to PNS exhibit decreases in dendritic length, spine density, and the number of neurons relative to non-stressed (NS) controls $(26,27)$. PNS also causes variable changes of gene expression in the brains of rats, including in genes associated with neural development, cell differentiation, and neurotransmitter function $(16,28,29)$. The frontal poles of PNS rat brains exhibit significant changes in genes associated with postsynaptic density complexes and vesicle exocytosis machinery, including the N-methyl-D-aspartate (NMDA) receptor 1 and 2A subunits, leucine-rich repeat domain-containing proteins (6), brain-enriched guanylate kinase-associated proteins, synaptosomal-associated proteins (24), synaphin/complexin, and vesicle-associated membrane protein 2 (16). A recent study utilizing microarray-based profiling of the hippocampus and frontal cortex investigated changes in gene expression following PNS and identified changes in genes supporting biological processes and/or signal transduction cascades that underlie glutamatergic and $\gamma$-aminobutyric acid (GABA)-ergic neurotransmission, mitogen-activated protein kinase (MAPK) signaling, neurotrophic factor signaling, phosphodiesterase (PDE)/cyclic nucleotide signaling, glycogen synthase kinase 3 (GSK3) signaling, and insulin signaling (28). Furthermore, Mairesse et al (29) observed alterations in protein expression in the hippocampi of PNS rats and confirmed changes in proteins, such as the LIM and SH3 protein 1 (Lasp1), prohibitin, fascin and transferrin.

Previous findings such as those have led to the hypothesis that PNS-induced phenomena alter the expression of schizophrenia-associated genes via proteomic mechanisms and that these genes ultimately affect susceptibility to schizophrenia in humans. Thus, in the present study, changes in protein expression were examined in the prefrontal cortex and hippocampus of rats exposed to repeated variable PNS. Furthermore, we investigated whether these genes were associated with susceptibility to schizophrenia in humans using genotyping and functional assays of the polymorphisms.

\section{Subjects and methods}

Animals and stress paradigm. Previously used, pregnant, Sprague-Dawley female rats were purchased from the Central Laboratory Animal Inc. (Seoul, Korea) and arrived at the animal facility on day 7 of gestation. The rats were housed under standard conditions with a 12:12-h light/dark cycle (lights on at 06:30) with free access to food and water. Animal procedures were performed in accordance with the guidelines for the care and use of laboratory animals of the National Institutes of Health of the US.

Beginning on day 14 of gestation, exposure to PNS was initiated and consisted of: i) restraint in well-ventilated cylindrical Plexiglas restrainers for $1 \mathrm{~h}$, ii) exposure to a cold environment $\left(4^{\circ} \mathrm{C}\right)$ for $6 \mathrm{~h}$, iii) overnight food deprivation, iv) $15 \mathrm{~min}$ of swim stress in room-temperature water, v) reversal of the light-dark cycle, and/or vi) social stress induced by overcrowded housing conditions during the dark phase of the cycle $(15,16)$. Pregnant dams used as controls remained in the animal room from gestational days 14-21 and were exposed to only normal animal-room husbandry procedures. Following birth, the dams and their pups were left undisturbed in their cages until weaning on postnatal day 23. At this time, male and female offspring were separated and group-housed in cages with one or two same-gender littermates with free access to rat chow and water. The animals were exposed to normal animal room conditions from that point onwards until experimental use on postnatal day $35(16,17)$.

Behavioral measures. Modified behavioral tests, including a social interaction test, the open field test, and the forced swim test, were performed, as previously described (15,30-32). The social interaction test was adapted from previous studies $(15,31,32)$ and was conducted in a clear Plexiglas chamber $(77 \times 77 \times 25 \mathrm{~cm})$. The room in which the chamber was located was darkened during testing, and the chamber was illuminated by a single $25 \mathrm{~W}$ red light bulb placed $\sim 100 \mathrm{~cm}$ above the base of the chamber (subject age, 30 days). The sessions were filmed with a video camera (Samsung, Seoul, Korea) placed $150 \mathrm{~cm}$ above the cage. The investigator remained outside the test room during testing, and the test arena was cleaned after each test session. Social interaction partners were same-gender siblings who resided in the same cage after weaning and were of approximately equal body weight (in the few cases in which a same-gender sibling was not available, a playmate from similar conditions was used). Each session lasted for $20 \mathrm{~min}$ and was scored in terms of the total duration of social play and the number and types of interactions. Specifically, a rater blind to the treatment conditions scored behaviors as aggressive [fighting (kicking, boxing, and wrestling), aggressive grooming and biting] or non-aggressive (sniffing, following and grooming the partner) based on the video. Experimental and target rats were not used in this paradigm more than once, and the arena was cleaned with $70 \%$ ethanol after each trial.

The open field test was used to assess exploratory activity and reactivity to a novel environment. On the test day, subjects were removed from their home cage (subject age, 32 days) and individually placed in the start box $(15 \times 15 \times 20 \mathrm{~cm})$ of the open field arena $(77 \times 77 \times 25 \mathrm{~cm})$ for $5 \mathrm{~min}$. The apparatus was composed of black Polygal, and no background noise was provided. The investigator exited the room, and the behavior of the subject was recorded. Scoring included central boxes entered, line crossings, runs, rears, grooming, cage sniffs and immobile behavior, as previously described $(30,31)$.

As described by previous studies $(30,31)$ the modified forced swim test was used (subject age, 34 days). The rats were individually lowered into a cylinder (height, $40 \mathrm{~cm}$; diameter, $20 \mathrm{~cm})$ filled with fresh heated tap water $\left(25 \pm 2^{\circ} \mathrm{C}\right)$. After $5 \mathrm{~min}$, the rat was removed and wiped with a clean towel to remove excess water prior to being returned to its home cage. On the following day, each rat was again placed in the cylinder for 15 min during which time swimming, climbing and immobility behaviors were recorded via video camera and by an observer using a stopwatch. The predominant behaviors were counted every $5 \mathrm{sec}$. Test scores were recorded and included swim behaviors (horizontal movement throughout the chamber and crossing quadrants), climbing behavior (upward-directed movements up the side of the chamber and jump-ups from the bottom of the chamber), and immobility 
(no additional activity other than keeping the head above water or tiny whip kicks) $(30,31)$.

Two-dimensional gel electrophoresis. PNS adult offspring and NS adult controls were sacrificed, and their brains were dissected to yield prefrontal cortical and hippocampal tissues. The tissues were washed twice with ice-cold phosphate-buffered saline, sonicated in sample-lysis solution, incubated at room temperature for $1 \mathrm{~h}$, and then centrifuged for $1 \mathrm{~h}$ at $15,000 \mathrm{x} \mathrm{g}$. The resulting supernatant fraction was then subjected to two-dimensional gel electrophoresis (2DE); $40-\mu \mathrm{g}$ samples of protein were separated by first-dimension isoelectric focusing using an immobilized dry strip $(13 \mathrm{~cm}$, 3-11NL) and, subsequently, electrophoresis using a $12 \%$ sodium dodecyl sulfate polyacrylamide gel electrophoresis (SDS-PAGE) gel. The samples were then stained with silver nitrate, and the strips were subjected to isoelectric focusing at $20^{\circ} \mathrm{C}$ in a Multiphor II electrophoresis unit connected to an EPS 3500 XL power supply (Amersham Biosciences, Uppsala, Sweden). After focusing, the equilibrated strips were placed on polyacrylamide gels $(20 \times 24 \mathrm{~cm})$ containing a gradient of 10-16\% SDS, and SDS-PAGE was performed using a Hoefer DALT 2D system (Amersham Biosciences) according to the manufacturer's instructions. Digitized images of the 2DE gels were quantitatively analyzed using PDQuest software (version 7.0; Bio-Rad, Seoul, Korea) according to the manufacturer's instructions. The intensity of each protein spot was normalized to the total valid spot intensity. The intensities of the corresponding protein spots from the control and PNS model samples were compared, and spots yielding differences of $\geq 50 \%$ between groups were selected for subsequent analysis.

MALDI-TOF analysis and database search. Peptides were evaporated with an N2 laser at $337 \mathrm{~nm}$ using a delayed extraction approach, and protein analyses were performed using an Ettan matrix-assisted laser desorption/ionization time-of-flight (MALDI-TOF) analysis (Amersham Biosciences, Piscataway, NJ, USA). The search program Mascot, developed by the Matrixscience (http://www.matrixscience.com/), was utilized for protein identification using peptide mass fingerprinting, and spectra were calibrated with trypsin auto-digestion ion peak m/z (842.5099, 2211.1046).

Immunohistochemistry. The rats were deeply anaesthetized with ethyl ether and perfused with $4 \%$ paraformaldehyde. Fixed brains were removed, frozen, and cut into $30-\mu \mathrm{m}$ sections using a sliding microtome. To detect dihydropyrimidinase-like 2 (Dpysl2 and Dpysl3 expression, frozen sections from the rat prefrontal cortex and hippocampus were blocked with horse and donkey serum, incubated with anti-Dpysl 2 (1:400; Cell Signaling Technology, Beverly, MA, USA) and Dpysl3 antibody (1:1,000; EMD Millipore Corp., Billerica, MA, USA) and then incubated with a Cy3-conjugated antirabbit secondary antibody (1:2,000; Jackson ImmunoResearch Laboratories, Inc., West Grove, PA, USA). Fluorescence images were captured using a confocal laser scanning microscope (FV10-ASW; Olympus, Tokyo, Japan), and image quantification was performed with ImageJ software using a previously described protocol with slight modifications (33). Briefly, the pixel intensities in the enlarged images $(x 400)$ were calibrated by setting the display value range (black) to 255 (green). The threshold level of detection was selected by viewing histograms and then adjusted to distinguish the intensity of the signal from that of the non-specific background. The same threshold level was used for all the images to allow for valid comparisons between the control and PNS model images. The intensity of the labeling was determined using 700-pixel boxes randomly placed at different locations on the labeled area, and background intensity was determined using boxes positioned in areas of no signal.

Western blot analysis. Prefrontal cortical and hippocampal tissues were lysed in radioimmunoprecipitation assay (RIPA) buffer containing protease inhibitors and then centrifuged at $18,341 \mathrm{x} \mathrm{g}$ for $10 \mathrm{~min}$ at $4^{\circ} \mathrm{C}$. To identify Dpysl2 and Dpysl3, 100 and $20 \mu \mathrm{g}$, respectively, of the lysed protein were placed on a $10 \%$ SDS gel and transferred onto a polyvinylidene difluoride (PVDF) membrane (EMD Millipore Corp.). After blocking with $5 \%$ skim milk, the membranes were probed with anti-Dpysl2 (1:200; Cell Signaling Technology, Inc.; Boston, MA, USA), anti-Dpys13 (1:20,000; EMD Millipore Corp.), and anti- $\beta$-actin (Actb; 1:5,000) antibody overnight at $4^{\circ} \mathrm{C}$ and then with peroxidase-conjugated secondary antibody $(1: 2,000)$ (both from Santa Cruz Biotechnology, Inc., Santa Cruz, CA, USA) for $1 \mathrm{~h}$ at room temperature. Immunoreactive bands were detected using an Enhanced Chemiluminescence (ECL) kit (Elpis Biotech Inc., Daejeon, Korea), and quantitative measurements of Dpys12, Dpysl3 and the Actb protein were obtained using ImageJ software. The mean pixel intensities of Dpys12, Dpysl3 and the Actb protein were measured by positioning a box around the protein band and subtracting the background intensity. The integrated density values were presented as means \pm standard error of the mean (SEM) of the individual protein levels normalized to the integrated density value of Actb. Quantitative measurements of Dpys12, Dpys13 and Actb were achieved using ImageJ software (http://imagej. nih.gov/ij). The mean pixel intensities of Dpys12, Dpysl3 and Actb were measured by positioning a box around the protein band and eliminating the background.

Subjects. This study included 202 patients with schizophrenia (118 male and 84 female) with a mean age of $46.08 \pm 11.9$ years (mean \pm SD) and 317 control subjects (144 male and 173 female) with a mean age of $44.04 \pm 7.8$ years (mean \pm SD) who had no clinical evidence of any psychiatric disorders. Blood samples were obtained from the schizophrenic and control participants at Soonchunhyang University Hospital and Kyung Hee University Hospital. The patients with schizophrenia were diagnosed according to the Diagnostic and Statistical Manual of Mental Disorders IV (DSM-IV) (34) by two well-trained psychiatrists. Control subjects were recruited following determination that they were mentally fit during an examination provided through a general health checkup program. Written informed consent was obtained from each subject.

Single-nucleotide polymorphism selection. To evaluate the association between the DPYSL2 gene and schizophrenia, seven single-nucleotide polymorphisms (SNPs) of DPYSL2 were genotyped in a Korean population. Five of the seven SNPs were previously described in a Japanese population 
Table I. Polymerase chain reaction primers for single-nucleotide polymorphisms in DPYSL2.

\begin{tabular}{|c|c|c|c|c|}
\hline SNP & Primer sequences & $\begin{array}{c}\text { Annealing } \\
\text { temperature }\left({ }^{\circ} \mathrm{C}\right)\end{array}$ & $\begin{array}{l}\text { Product size } \\
\quad(\mathrm{bp})\end{array}$ & $\begin{array}{c}\text { Restriction } \\
\text { enzyme }\end{array}$ \\
\hline $\begin{array}{l}\text { rs9886448 } \\
(-1625 T>C)\end{array}$ & $\begin{array}{l}\text { F: 5'-GAAGCCAGACTTTGAGGTGGA-3' } \\
\text { R: 5'-GCACTGCTTTCCAGGTTAGG-3' }\end{array}$ & 58 & 120 & N/A \\
\hline $\begin{array}{l}\operatorname{rs} 4872449 \\
(-1195 \mathrm{~A}>\mathrm{G})\end{array}$ & $\begin{array}{l}\text { F: 5'-CCGCACTTACTCCCCAAACA-3' } \\
\text { R:5'-ACGTGTCGCGATTTGGTTTA-3' }\end{array}$ & 52 & 317 & SmaI \\
\hline $\begin{array}{l}\text { rs } 431246 \\
(-975 C>G)\end{array}$ & $\begin{array}{l}\text { F: 5'-GCCCATTCCCCGCCCCCAGGAG-3' } \\
\text { R: 5'-CCCGCCGTTGCTGGCGCTGAAC-3' }\end{array}$ & 70 & 169 & Alw62I \\
\hline $\begin{array}{l}\text { rs } 2289593 \\
(352 \mathrm{G}>\mathrm{A})\end{array}$ & $\begin{array}{l}\text { F: 5'-ACCTACCGTGATCCTTCACAAG-3' } \\
\text { R:5'-AGCTGGGTTACATGGATTCTTA-3' }\end{array}$ & 53 & 327 & Fnu4HI \\
\hline $\begin{array}{l}\text { rs } 327222 \\
(426 \mathrm{C}>\mathrm{T})\end{array}$ & $\begin{array}{l}\text { F: 5'-ACTACTCTCTGCATGTGGACATCCG-3' } \\
\text { R: 5'-GAGGGCATTGACTCAGTGCAACCTA-3' }\end{array}$ & 62 & 104 & $B s h 1236 \mathrm{I}$ \\
\hline $\begin{array}{l}\text { rs708621 } \\
(1506 \mathrm{~T}>\mathrm{C})\end{array}$ & $\begin{array}{l}\text { F: 5'-GCTGAGCTGAGAGGCGTTCCTC-3' } \\
\text { R: 5'-CCTGCTGCTTGGCAGGAGACGT-3' }\end{array}$ & 56 & 118 & $B s p \mathrm{LI}$ \\
\hline $\begin{array}{l}\text { rs17666 } \\
(* 2236 \mathrm{~T}>\mathrm{C})\end{array}$ & $\begin{array}{l}\text { F: 5'-GTCTTCCTGTTTTTCCTGTACC-3' } \\
\text { R: 5'-TATTTTGCCATCAAGACAGTGG-3' }\end{array}$ & 56 & 367 & BspTI \\
\hline
\end{tabular}

N/A, not applicable; SNP, single-nucleotide polymorphisms; DPYSL2, dihydropyrimidinase-like 2; F, forward; R, reverse.

(rs431246, promoter; rs2289593, missense; rs327222, synonymous; rs708621, synonymous; and rs17666, 3'UTR) (35) and two promoter SNPs (rs4872449 and rs9886448) were added using the National Center for Biotechnology Information (NCBI) website (http://www.ensembl.org; www.ncbi. nlm.nih.gov/SNP). Of the SNPs for DPYSL2, all coding SNPs (cSNPs) and all SNPs of the promoter region of the gene $(\sim 2,000$ bp upstream) were initially selected. Of these, SNPs with $>5 \%$ minor allele frequency (MAF) and $>10 \%$ heterozygosity and/or genotype frequencies in the Asian population were included.

Genotyping. DNA was extracted from peripheral blood using a PureHelix Genomic DNA Prep kit (NanoHelix Co., Ltd., Daejeon, Korea) (36), as previously described. The primer sequences and annealing temperatures used for the analysis of each polymorphism are provided in Table I. Each reaction consisted of a single denaturation at $95^{\circ} \mathrm{C}$ for $5 \mathrm{~min}$, 35 cycles of denaturation at $95^{\circ} \mathrm{C}$ for $30 \mathrm{sec}$, annealing at the appropriate primer pair with an annealing temperature for $30 \mathrm{sec}$, and then an extension at $72^{\circ} \mathrm{C}$ for $30 \mathrm{sec}$. A final extension step at $72^{\circ} \mathrm{C}$ was performed at the end of the program for $10 \mathrm{~min}$. Following amplification, the polymerase chain reaction $(\mathrm{PCR})$ products were digested overnight with the corresponding restriction enzyme (Table I) according to the manufacturer's instructions. The digestion products were subsequently electrophoresed on $3.0 \%$ agarose gels and stained with SYBR-Green (Invitrogen, Carlsbad, CA, USA). One of the seven SNPs (rs9886448) was analyzed using the high-resolution melt (HRM) method of the $\mathrm{Eco}^{\mathrm{TM}}$ Real-Time PCR System (Illumina, Inc., San Diego, CA, USA). The reaction was initiated with a single denaturation at $95^{\circ} \mathrm{C}$ for $10 \mathrm{~min}$, followed by 40 three-step cycles of denaturation at $95^{\circ} \mathrm{C}$ for $10 \mathrm{sec}$ each, annealing at the appropriate primer-pair annealing temperature for $15 \mathrm{sec}$, and then an extension at $72^{\circ} \mathrm{C}$ or $15 \mathrm{sec}$. Subsequently, the PCR products were heated to $95^{\circ} \mathrm{C}$ for $15 \mathrm{sec}$ and then cooled down to $55^{\circ} \mathrm{C}$ for $15 \mathrm{sec}$. The melt curves were then produced by measuring fluorescence during a temperature increase from $55^{\circ} \mathrm{C}$ to $95^{\circ} \mathrm{C}$ (with $0.1^{\circ} \mathrm{C}$ increments).

Statistical analysis. Western blot analysis and immunohistochemical image quantifications were performed using ImageJ software. Groups were compared using Student's t-test, and $\mathrm{P}<0.05$ was considered to indicate a significant result. The Hardy-Weinberg equilibrium (HWE) was assessed using the SNPstats program (http://bioinfo.iconcologia.net/SNPstats), and Haploview version 4.2 (Daly Lab Inc., Cambridge, MA, USA) was employed to determine the linkage disequilibrium (LD) block. SNPStats was used to evaluate the odds ratios (ORs), 95\% confidence intervals (CIs), and P-values. The multiple logistic regression analyses were conducted using age and gender as covariates and Bonferroni's correction was applied by multiplying the P-values by the number of SNPs $(n=7)$.

\section{Results}

Social interaction test. Slight differences between the NS and PNS groups were observed (Table II). In particular, one of the non-aggressive behaviors, i.e., that of partner grooming, was significantly decreased in the PNS group $(\mathrm{P}=0.011)$

The open-field test. NS and PNS offspring were tested in the open field for $20 \mathrm{~min}$. The PNS group had a significantly greater number of line crossings $(\mathrm{P}=0.014)$ and showed a trend towards a greater number of entries into the center $(\mathrm{P}=0.068)$ (Table III) relative to the NS group. 
Table II. Social interaction behavior of non-prenatal stress and prenatal stress-induced rat.

\begin{tabular}{lccc}
\hline Behavior & NS & PNS & P-value \\
\hline Non-aggressive & & & \\
Sniffing (n) & $18.4 \pm 2.26$ & $17.1 \pm 2.79$ & 0.722 \\
Sniffing (s) & $74.7 \pm 13.62$ & $65.7 \pm 11.24$ & 0.617 \\
Following (n) & $14 \pm 2.29$ & $9.62 \pm 2.13$ & 0.059 \\
Following (s) & $55.6 \pm 9.24$ & $41.37 \pm 8.72$ & 0.095 \\
Grooming the partner (n) & $2.2 \pm 0.69$ & $0.29 \pm 0.18$ & $\mathbf{0 . 0 1 1}$ \\
Grooming the partner (s) & $16 \pm 7.73$ & $5.43 \pm 4.64$ & 0.164 \\
Aggressive & & & \\
Fight (n) & $5 \pm 1.14$ & $3.16 \pm 1.4$ & 0.173 \\
Fight (s) & $20 \pm 9.08$ & $19.16 \pm 8.47$ & 0.645 \\
Aggressive grooming (n) & $1 \pm 0.00$ & $1 \pm 0.00$ & 1.000 \\
Aggressive grooming (s) & $4 \pm 0.00$ & $3 \pm 0.00$ & 0.844 \\
Biting (n) & $2.5 \pm 1.50$ & $4 \pm 0.00$ & 0.104 \\
Biting (s) & $14.5 \pm 9.50$ & $16 \pm 0.00$ & 0.112 \\
\hline
\end{tabular}

Bold, significant decrease. Data are presented as mean \pm SEM; $n$, number of the behavior; s, duration measured in seconds; NS, nonstressed group; PNS, prenatally-stressed group; SEM, standard error of the mean.

Table III. Behavior of non-prenatal stress and prenatal stress induced rat in an open field.

\begin{tabular}{lccc}
\hline Behavior & NS & PNS & P-value \\
\hline Centrally entered (n) & $5.1 \pm 1.87$ & $1.3 \pm 0.57$ & 0.068 \\
Line crossing (n) & $1.8 \pm 0.46$ & $0.4 \pm 0.22$ & 0.014 \\
Run (n) & $15.8 \pm 3.69$ & $17.4 \pm 0.37$ & 0.753 \\
Run (s) & $19 \pm 4.32$ & $26 \pm 5.96$ & 0.316 \\
Rear (n) & $44.2 \pm 7.81$ & $35.6 \pm 3.26$ & 0.323 \\
Rear (s) & $103.2 \pm 24.90$ & $82.4 \pm 13.36$ & 0.471 \\
Grooming (n) & $13.7 \pm 1.14$ & $14.4 \pm 0.81$ & 0.625 \\
Grooming (s) & $283.3 \pm 34.15$ & $283.4 \pm 24.41$ & 0.998 \\
Cage sniff (n) & $22.3 \pm 2.35$ & $25.8 \pm 4.27$ & 0.482 \\
Cage sniff (s) & $62.3 \pm 7.94$ & $84.3 \pm 18.32$ & 0.285 \\
Immobile (n) & $7.8 \pm 1.83$ & $12.1 \pm 2.07$ & 0.139 \\
Immobile (s) & $208.9 \pm 55.06$ & $263.8 \pm 47.39$ & 0.460
\end{tabular}

Data are presented as mean \pm SEM. $n$, number of the behavior; $\mathrm{s}$, duration measured in seconds; NS, non-stressed group; PNS, prenatally-stressed group; SEM, standard error of the mean.

The forced swim test. In the forced swim test, PNS offspring exhibited fewer immobility behaviors compared with NS rats $(\mathrm{P}=0.029)$ (Table IV and Fig. 1). However, the climbing and swimming behaviors of the two groups did not differ $(\mathrm{P}>0.05)$.

Proteomic analysis. To compare protein expression in the prefrontal cortices and hippocampi of PNS and NS rats, the soluble proteins were extracted and evaluated on non-linear
Table IV. Behavioral response in the forced swim test session.

\begin{tabular}{lrrr}
\hline Behavior & \multicolumn{1}{c}{ NS } & PNS & P-value \\
\hline Climbing & $75 \pm 7.56$ & $81 \pm 10.87$ & 0.656 \\
Swimming & $103 \pm 5.06$ & $74 \pm 11.12$ & 0.029 \\
Immobility & $122 \pm 6.79$ & $144 \pm 15.08$ & 0.191 \\
\hline
\end{tabular}

Data are presented as mean \pm SEM. NS, non-stressed group; PNS, prenatally-stressed group; SEM, standard error of the mean.

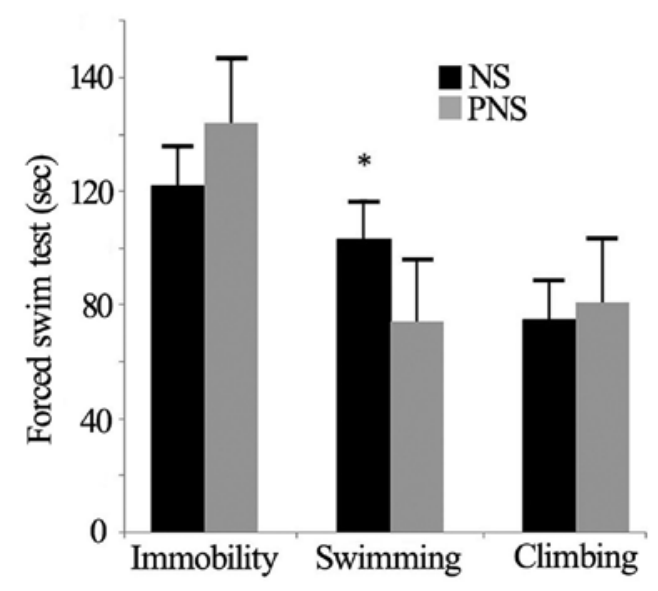

Figure 1. Behavioral response in the forced swim test. Comparison between NS and PNS offspring ( $n=10$ in each group). Marks indicate a decrease in swimming. Data are presented as means \pm SEM. ${ }^{*} \mathrm{P}<0.05$. NS, non-prenatal stressed offspring; PNS, prenatal stressed offspring; SEM, standard error of the mean.

pH 3-11 gel strips. From the silver-stained 2D gels, 360 protein spots in the prefrontal cortex and 349 protein spots in the hippocampus were visualized (Fig. 2). Of these, 31 protein spots in the prefrontal cortex and 30 protein spots in the hippocampus differed significantly according to the MALDI-TOF analyses (95\% CI). Compared with the NS group following triplicate runs, the PNS group had five protein spots that were upregulated and 26 spots that were downregulated in the prefrontal cortex (Table V). Additionally, five spots were upregulated in the hippocampus and 30 spots were downregulated in the PNS compared with the control rats (Table VI).

Confirmation of downregulated proteins in PNS rats. Dpysl2 is expressed in neurons of the central nervous system and is concentrated at synaptic sites and in the axon, where it may affect synaptic physiology (34). To confirm the PNS-induced downregulation of Dpys12 and Dpys 13 proteins observed in our proteomics study (Fig. 3), we performed western blotting (Figs. 4 and 5) and immunohistochemical (Fig. 6) analyses of the hippocampal and prefrontal cortex areas of the control and PNS rat brains. In the western blot analyses used to assess the Dpysl2 and Dpysl3 proteins, 100 and $20 \mu \mathrm{g}$ of the lysed protein, respectively, were electrophoresed on a $10 \%$ SDS-PAGE gel and then transferred onto a PVDF membrane. The membranes were probed with anti-Dpys12, anti-Dpysl3 and anti-Actb antibody overnight and then with 
NS
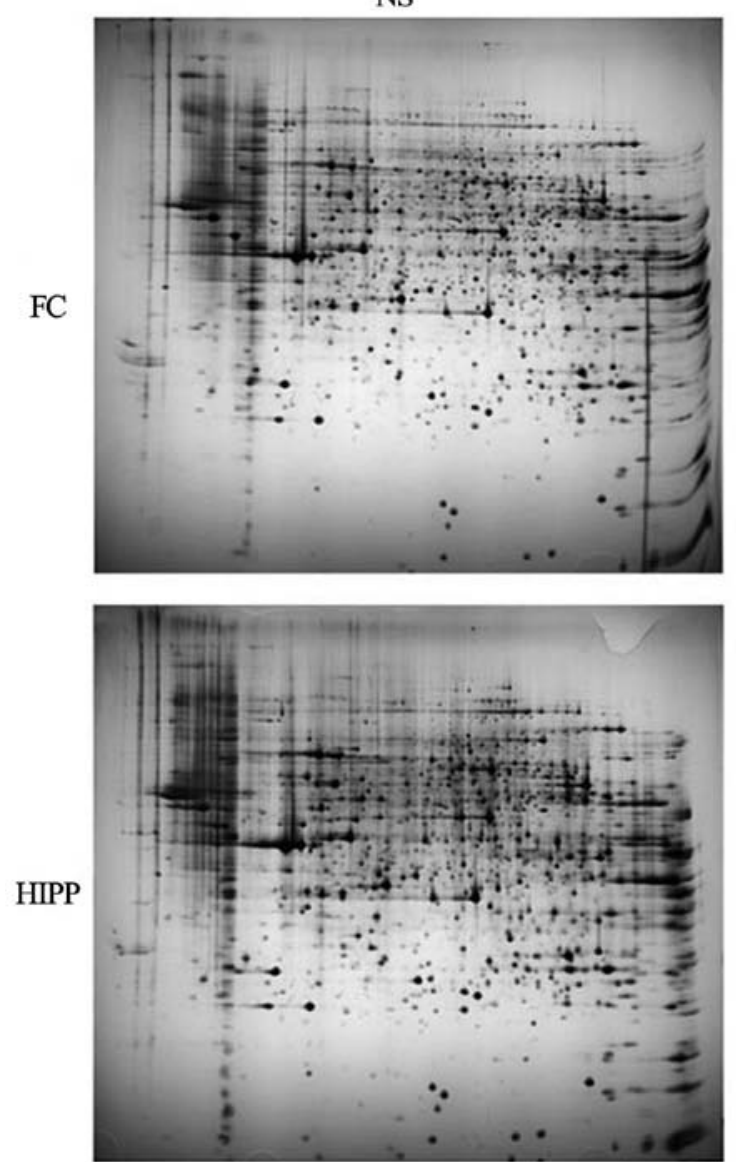

PNS
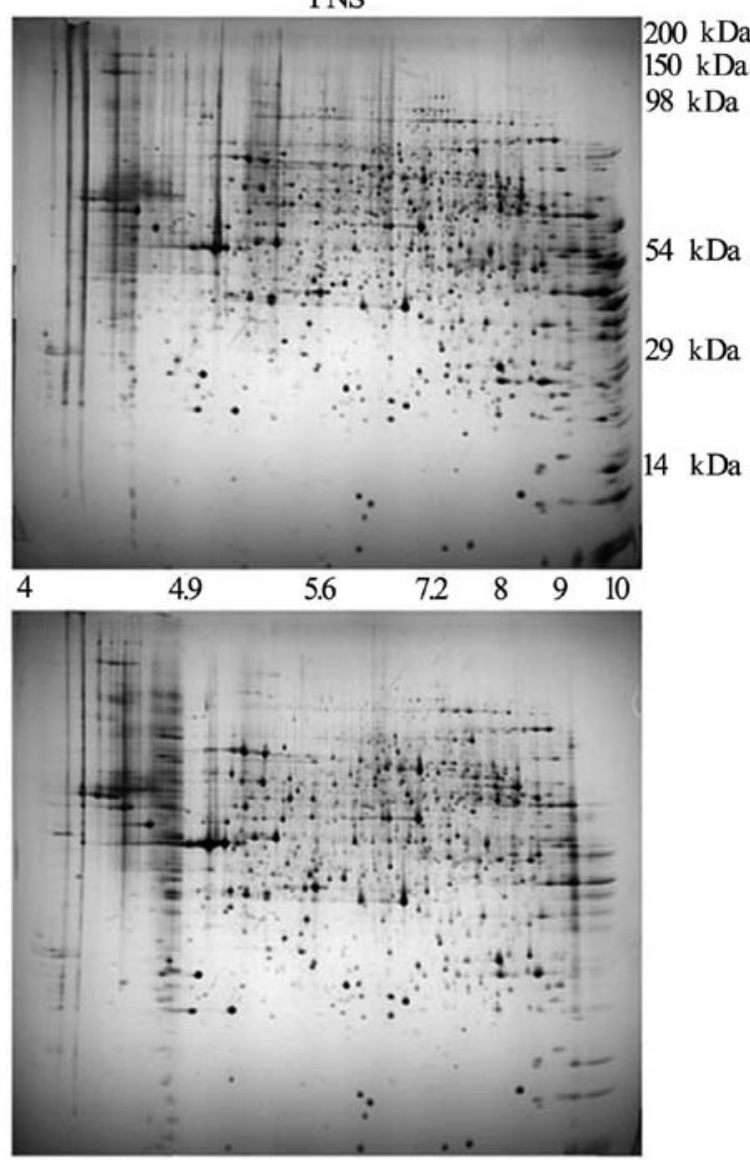

Figure 2. Protein profiles of two-dimensional gel electrophoresis. FC, prefrontal cortex; Hipp, hippocampus; NS, non-prenatal stressed offspring; PNS, prenatal stressed offspring.

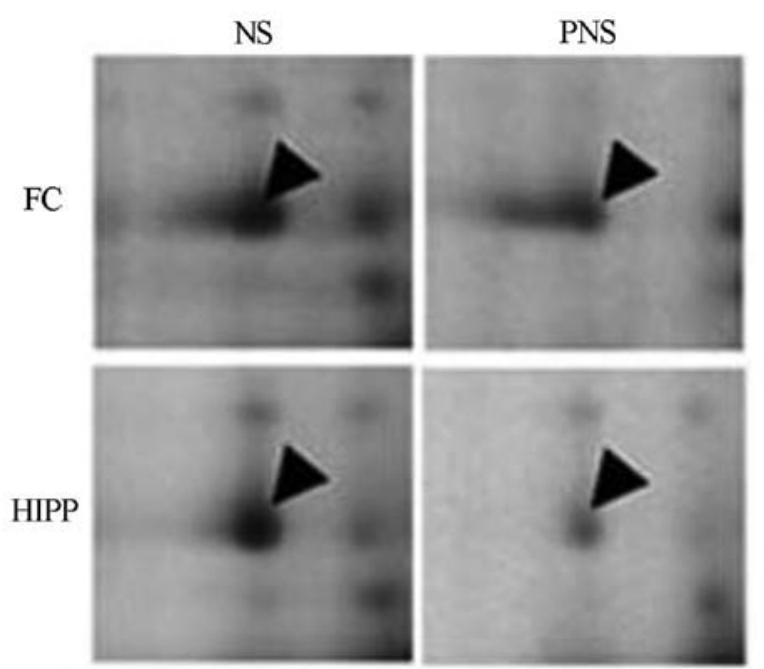

Dpys12
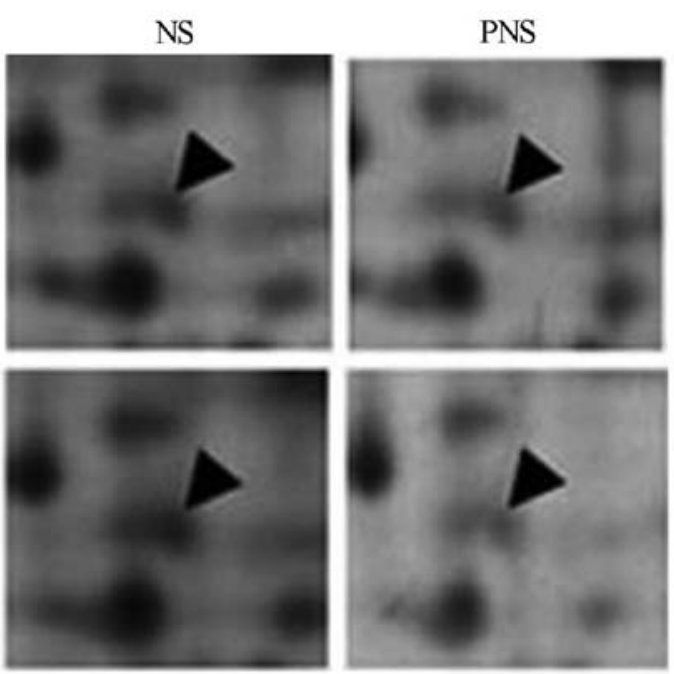

Dpysl3

Figure 3. Two-dimensional gel electrophoresis patterns of protein expression in rat brains for two selected proteins. FC, prefrontal cortex; Hipp, hippocampus; NS, non-prenatal stressed offspring; PNS, prenatal stressed offspring. Arrowheads are protein spots, showing different changes among the groups.

peroxidase-conjugated secondary antibodies prior to immunoreactive bands being detected using the ECL kit. Western blot analyses revealed that the amount of Dpysl 2 protein in the prefrontal cortex and hippocampus was significantly lower in PNS than in NS rats (all P-values <0.05) (Fig. 4), whereas the amount of Actb in the prefrontal cortex and hippocampus 
Table V.A list of prefrontal cortex proteins that are differentially expressed in non-prenatal stress and prenatal stress-induced rats.

\begin{tabular}{|c|c|c|c|c|c|c|}
\hline Protein description & Access no. & $\begin{array}{l}\text { Nominal } \\
\text { mass }\end{array}$ & $\mathrm{pI}$ & Score & Fold-change $^{c}$ & $\begin{array}{l}\text { Coverage } \\
(\%)\end{array}$ \\
\hline \multicolumn{7}{|l|}{ Upregulated in prenatal stress induced rat } \\
\hline Phosphoglycerate mutase 1 & gil114326546 & 28928 & 6.67 & 88 & $>200$ & 55 \\
\hline Protein carboxyl methyltransferase & gil603467 & 24667 & 7.14 & 61 & 200 & 29 \\
\hline GTP-binding nuclear protein Ran & gil5453555 & 24579 & 7.01 & 113 & 200 & 55 \\
\hline p55 protein & gil83320109 & 51317 & 6.01 & 62 & 2.3 & 29 \\
\hline Proteasome subunit $\alpha$ type- 2 & gil8394063 & 26024 & 6.92 & 87 & 1.3 & 38 \\
\hline \multicolumn{7}{|l|}{ Downregulated in prenatal stress induced rat } \\
\hline Dihydropyrimidinase-like 2 & gil40254595 & 62638 & 5.95 & 233 & 0.7 & 48 \\
\hline Septin-6 & gil290677865 & 49147 & 6.23 & 191 & 0.7 & 38 \\
\hline Dihydropyrimidinase-like 3 & gil25742568 & 62327 & 6.04 & 114 & 0.7 & 31 \\
\hline Vinculin & gil157822133 & 117112 & 5.83 & 223 & 0.7 & 28 \\
\hline $\begin{array}{l}\text { Glycerol-3-phosphate dehydrogenase }\left[\mathrm{NAD}^{+}\right] \text {, } \\
\text { cytoplasmic }\end{array}$ & gil57527919 & 38112 & 6.16 & 151 & 0.7 & 48 \\
\hline Dihydropyrimidinase-like 2 & gil40254595 & 62638 & 5.95 & 102 & 0.6 & 26 \\
\hline Dihydropyrimidinase-like 2 & gil40254595 & 62638 & 5.95 & 178 & 0.6 & 44 \\
\hline Dihydropyrimidinase-like 3 , isoform $\mathrm{CRA}^{\mathrm{b}}$ & gil149017448 & 62141 & 6.04 & 104 & 0.6 & 28 \\
\hline Gelsolin, isoform $\mathrm{CRA}^{\mathrm{b}}$ & gil149038929 & 81064 & 5.46 & 92 & 0.58 & 22 \\
\hline Dihydropyrimidinase-like 2 & gil40254595 & 62638 & 5.95 & 150 & 0.56 & 36 \\
\hline $\begin{array}{l}\text { Inner membrane protein, mitochondrial, } \\
\text { isoform } \mathrm{CRA}^{\mathrm{a}}\end{array}$ & gil149036390 & 86204 & 5.67 & 124 & 0.55 & 26 \\
\hline NADH dehydrogenase (ubiquinone) & gil149046009 & 74362 & 5.74 & 229 & 0.49 & 35 \\
\hline \multicolumn{7}{|l|}{$\mathrm{Fe}-\mathrm{S}$ protein 1 , isoform $\mathrm{CRA}^{\mathrm{b}}$} \\
\hline Transitional endoplasmic reticulum ATPase & gil17865351 & 89977 & 5.14 & 227 & 0.42 & 37 \\
\hline Transitional endoplasmic reticulum ATPase & gil17865351 & 89977 & 5.14 & 206 & 0.41 & 32 \\
\hline Ubiquitin carboxyl-terminal hydrolase 14 & gil56605688 & 56397 & 5.11 & 65 & 0.4 & 22 \\
\hline $\begin{array}{l}\text { Inner membrane protein, mitochondrial, } \\
\text { isoform } \text { CRA }^{\mathrm{a}}\end{array}$ & gil149036390 & 86204 & 5.67 & 196 & 0.4 & 31 \\
\hline$\alpha$-internexin & gil55622 & 55712 & 5.2 & 327 & 0.4 & 47 \\
\hline Glial fibrillary acidic protein $\delta$ & gil5030428 & 48809 & 5.72 & 145 & 0.4 & 36 \\
\hline Glial fibrillary acidic protein & gil430721 & 49970 & 5.35 & 141 & 0.4 & 36 \\
\hline Coiled-coil domain containing 85A-like isoform 3 & gil293341895 & 50812 & 8.29 & 64 & 0.3 & 16 \\
\hline$\beta$-soluble NSF attachment protein & gil205829956 & 33791 & 5.32 & 233 & 0.29 & 75 \\
\hline$\alpha$-soluble NSF attachment protein & gil18034791 & 33627 & 5.3 & 236 & 0.2 & 73 \\
\hline Tpi1 protein & gil38512111 & 27214 & 7.07 & 187 & 0.2 & 65 \\
\hline Dynactin subunit 2 & gil51948450 & 44235 & 5.14 & 251 & 0.2 & 50 \\
\hline $\begin{array}{l}\text { Sirtuin (silent mating type information regulation } 2 \\
\text { homolog) } 2 \text { (S. cerevisiae), isoform } \mathrm{CRA}^{\mathrm{a}}\end{array}$ & gil149056443 & 43763 & 5.37 & 91 & 0.2 & 34 \\
\hline Serum albumin precursor & gil158138568 & 70710 & 6.09 & 284 & 0.2 & 49 \\
\hline
\end{tabular}

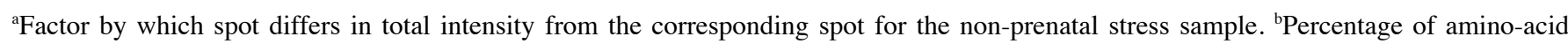
sequence covered by peptides in the MALDI-TOF MS analysis.

was similar in the two groups. Similar results were observed for Dpysl3 (all P-values $<0.05$ in the prefrontal cortex and hippocampus) (Fig. 5).

Immunohistochemical analysis. To detect Dpysl2 expression, the fixed brains were removed, frozen, and cut into $30-\mu \mathrm{m}$ sections. The frozen sections from the rat prefrontal cortices and hippocampi were incubated with individual antibodies of Dpysl2 and then incubated with a Cy3-conjugated anti-rabbit secondary antibody. The differential expression of the Dpysl2 proteins was evident in the immunofluorescence-stained images of NS and PNS rat brains and in the intensity measurements of the immunohistochemical staining of Dpysl 2 in these images $(\mathrm{P}<0.001$ for the prefrontal cortex and the hippocampus in Dpysl2) (Fig. 6).

Genetic association of DPYSL2 SNPs with schizophrenia in a Korean population. After identification of Dpysl2 as a 
A

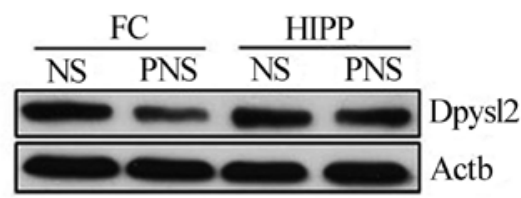

B

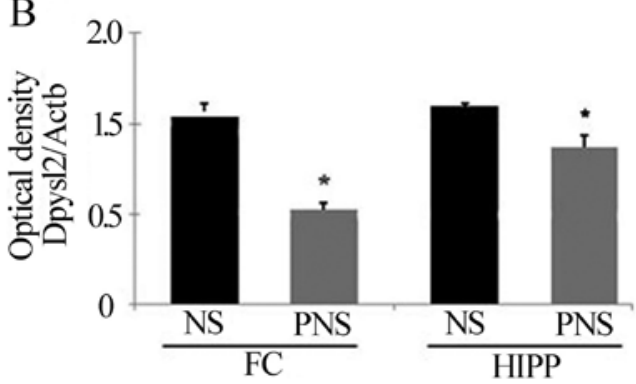

Figure 4. Western blot analysis of Dpys12 expression in the brains of PNS-induced rats. (A) Dpysl2 expression was detected by western blotting with Actb used as an internal control. PNS rats exhibited decreased Dpysl2 expression in the prefrontal cortex and hippocampus. (B) Quantitative analysis of western blot data for Dpys12 expression showing a significant difference in Dpys12 levels in PNS vs. control rat brains $\left({ }^{*} \mathrm{P}<0.05\right.$ compared with the NS group in the prefrontal cortex and hippocampus). Dpys12, dihydropyrimidinase-like 2; FC, prefrontal cortex; Hipp, hippocampus; NS, non-prenatal stressed offspring; PNS, prenatal stressed offspring; SD, standard deviation.

PNS-induced protein in the rat, the study was extended to human subjects. To evaluate whether genetic polymorphisms of the human DPYSL2 gene are associated with schizophrenia, seven SNPs (rs9886448, rs4872449, rs431246, rs2289593, rs327222, rs708621 and rs17666) were selected partially based on the identification of five SNPs (35) and two promoter SNPs of the DPYSL2 that may have affected gene expression in a previously described Japanese population. The genotyping of six SNPs was performed by enzyme digestion of the post-PCR product and by the HRM method for one SNP. The genotypic and allelic distributions of the SNPs in patients and control subjects are presented in Table VII. The genotype distributions of the seven SNPs were analyzed using HWE (P>0.05).

The heterozygous genotype (TC) frequency for rs 9886448 was lower in the schizophrenia group $(27.20 \%)$ than in the control group (41.64\%), and its genotypic frequency was statistically associated with schizophrenia in codominant models 1 and 2 [OR, 0.54 (1.20); 95\% CI, 0.36-0.80 (0.66-2.17); $\mathrm{P}=0.003$, $\mathrm{P}$-value corrected by the Bonferroni method, $\mathrm{Pc}=0.020]$ and in the overdominant model (OR, 0.52; 95\% CI, 0.36-0.77; $\mathrm{P}=0.001, \mathrm{Pc}=0.006)$. Furthermore, the allele frequency for rs2289593 was lower in the schizophrenia group (7.67\%) compared with the control group (14.2\%), and its genotypic frequency was statistically associated with schizophrenia in codominant models 1 and 2 [OR, 0.48 (0.29); 95\% CI, 0.29-0.79 (0.06-1.37); $\mathrm{P}=0.003, \mathrm{Pc}=0.023]$, the dominant model $(\mathrm{OR}$, $0.46 ; 95 \% \mathrm{CI}, 0.29-0.74 ; \mathrm{P}=0.001, \mathrm{Pc}=0.006)$, the overdominant model (OR, 0.49; 95\% CI, 0.30-0.81; $\mathrm{P}=0.004, \mathrm{Pc}=0.026)$, and the log-additive model (OR, 0.49; 95\% CI, 0.32-0.76; $\mathrm{P}=0.001$, $\mathrm{Pc}=0.006)$. The allele frequency of rs 2289593 was also associated with susceptibility to schizophrenia (OR, 0.50; 95\% CI, 0.33-0.77; $\mathrm{P}=0.002, \mathrm{Pc}=0.014$ ) (Table VII). No significant differences were found between patients and control subjects regarding the frequency of the genotype or allele in five of
A

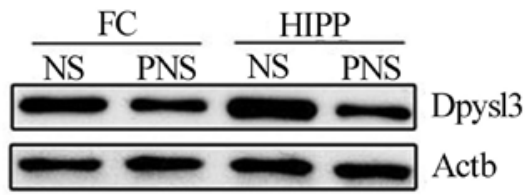

B

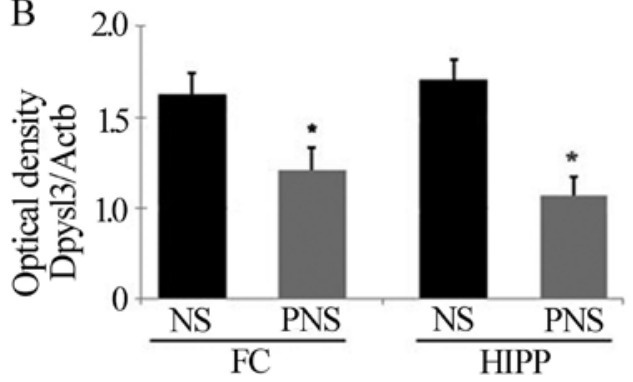

Figure 5. Western blot analysis of Dpys13 expression in the brains of PNS-induced rats. (A) Dpys13 expression was detected by western blotting with Actb used as an internal control. PNS rats exhibited decreased Dpysl3 expression in the prefrontal cortex and hippocampus. (B) Quantitative analysis of western blot data for Dpys13 expression showing a significant difference in Dpysl3 levels in PNS vs. control rat brains ( $\mathrm{P}<0.05$ compared with the NS group in the prefrontal cortex and hippocampus). Dpysl3, dihydropyrimidinase-like 3; FC, prefrontal cortex; Hipp, hippocampus; NS, non-prenatal stressed offspring; PNS, prenatal stressed offspring; SD, standard deviation.
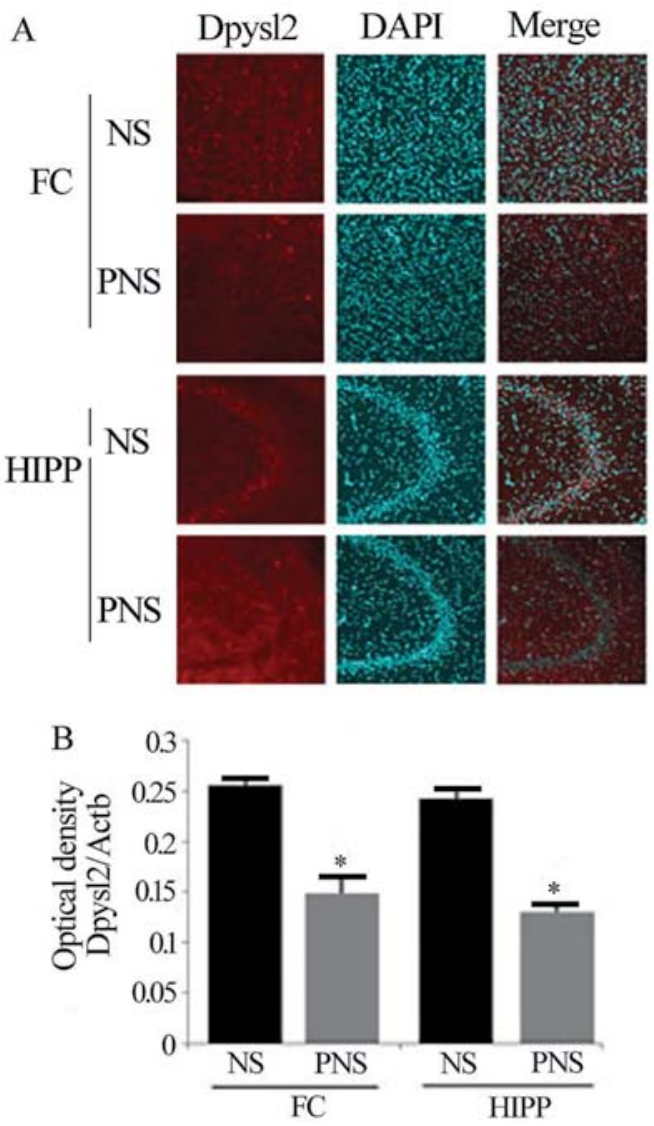

Figure 6. Immunohistochemical analysis of Dpys12 expression in the brains of PNS-induced rats. (A) Confocal microscopic image showing immunofluorescent staining for Dpys12 (anti-Dpys12, red, Cy3) with DAPI in the prefrontal cortex and hippocampus. Fluorescent staining revealed decreased Dpys12 in these regions. Scale bar, FC; 50 Hipp; $100 \mu \mathrm{m}$. (B) Optical densities of Dpys12 signals in immunostained prefrontal cotex and hippocampus sections from $\left({ }^{*} \mathrm{P}<0.05\right.$ compared with the NS group in the prefrontal cortex and hippocampus). Dpys12, dihydropyrimidinaselike 2; FC, prefrontal cortex; Hipp, hippocampus; NS, non-prenatal stressed offspring; PNS, prenatal stressed offspring; SD, standard deviation. 
Table VI. A list of hippocampal proteins that are differentially expressed in non-prenatal stress and prenatal stress-induced rats.

\begin{tabular}{|c|c|c|c|c|c|c|}
\hline Protein description & Access no. & $\begin{array}{l}\text { Nominal } \\
\text { mass }\end{array}$ & $\mathrm{pI}$ & Score & Fold-change $^{c}$ & $\begin{array}{l}\text { Coverage } \\
(\%)\end{array}$ \\
\hline \multicolumn{7}{|l|}{ Upregulated in prenatal stress induced rat } \\
\hline $\begin{array}{l}\text { NADH dehydrogenase (ubiquinone) } \mathrm{Fe}-\mathrm{S} \text { protein } 1 \text {, } \\
\text { isoform } \mathrm{CRA}^{\mathrm{b}}\end{array}$ & gil149046009 & 74362 & 5.74 & 229 & 1.23 & 35 \\
\hline Vinculin & gil157822133 & 117112 & 5.83 & 223 & 1.2 & 28 \\
\hline p55 protein & gil83320109 & 51317 & 6.01 & 62 & 1.1 & 29 \\
\hline$\alpha$-internexin & gil55622 & 55712 & 5.2 & 327 & 1.1 & 47 \\
\hline$\beta$-soluble NSF attachment protein & gil205829956 & 33791 & 5.32 & 233 & 1.07 & 75 \\
\hline \multicolumn{7}{|l|}{ Downregulated in prenatal stress induced rat } \\
\hline Dihydropyrimidinase-like 2 & gil40254595 & 62638 & 5.95 & 150 & 0.7 & 36 \\
\hline Dihydropyrimidinase-like 2 & gil40254595 & 62638 & 5.95 & 233 & 0.7 & 48 \\
\hline Tpi1 protein & gil38512111 & 27214 & 7.07 & 187 & 0.7 & 65 \\
\hline Dynamin-1 & gil190358918 & 97576 & 6.44 & 264 & 0.7 & 38 \\
\hline $\begin{array}{l}\text { Hydroxyacylglutathione hydrolase, } \\
\text { mitochondrial precursor }\end{array}$ & gil315630402 & 34593 & 8.06 & 78 & 0.7 & 34 \\
\hline Actin-related protein $2 / 3$ & gil205686193 & 34484 & 6.84 & 164 & 0.6 & 41 \\
\hline $\begin{array}{l}\text { Electron transfer flavoprotein subunit } \alpha \text {, } \\
\text { mitochondrial precursor }\end{array}$ & gil57527204 & 35272 & 8.62 & 146 & 0.6 & 38 \\
\hline $\begin{array}{l}\text { Glycerol-3-phosphate dehydrogenase }\left[\mathrm{NAD}^{+}\right] \text {, } \\
\text { cytoplasmic }\end{array}$ & gil57527919 & 38112 & 6.16 & 151 & 0.6 & 48 \\
\hline Glycogen phosphorylase, brain form & gil158187544 & 97361 & 6.31 & 125 & 0.6 & 14 \\
\hline Transitional endoplasmic reticulum ATPase & gil17865351 & 89977 & 5.14 & 206 & 0.57 & 32 \\
\hline Protein carboxyl methyltransferase & gil603467 & 24667 & 7.14 & 61 & 0.5 & 29 \\
\hline Proteasome subunit $\alpha$ type- 2 & gil8394063 & 26024 & 6.92 & 87 & 0.5 & 38 \\
\hline $\mathrm{N}$-acetylneuraminic acid synthase & gil164663874 & 40482 & 6.39 & 82 & 0.5 & 21 \\
\hline Ribose-phosphate pyrophosphokinase 1 isoform 1 & gil4506127 & 35325 & 6.51 & 85 & 0.5 & 24 \\
\hline Glycogen phosphorylase, brain form & gil158187544 & 97361 & 6.31 & 68 & 0.5 & 10 \\
\hline Septin-6 & gil290677865 & 49147 & 6.23 & 191 & 0.5 & 38 \\
\hline Dihydropyrimidinase-like 3 & gil25742568 & 62327 & 6.04 & 114 & 0.5 & 31 \\
\hline $\begin{array}{l}\text { Sirtuin (silent mating type information regulation } 2 \\
\text { homolog) } 2(S \text {. cerevisiae }) \text {, isoform } \mathrm{CRA}^{\mathrm{a}}\end{array}$ & gil149056443 & 43763 & 5.37 & 91 & 0.47 & 34 \\
\hline GTP-binding nuclear protein Ran & gil5453555 & 24579 & 7.01 & 113 & 0.4 & 55 \\
\hline $\begin{array}{l}\text { Hydroxyacylglutathione hydrolase, } \\
\text { mitochondrial precursor }\end{array}$ & gil315630402 & 34593 & 8.06 & 76 & 0.4 & 30 \\
\hline Ubiquitin carboxyl-terminal hydrolase 14 & gil56605688 & 56397 & 5.11 & 65 & 0.4 & 22 \\
\hline$\alpha$-soluble NSF attachment protein & gil18034791 & 33627 & 5.3 & 236 & 0.4 & 73 \\
\hline Coiled-coil domain containing 85A-like isoform 3 & gil293341895 & 50812 & 8.29 & 64 & 0.3 & 16 \\
\hline Dihydropyrimidinase-like 2 & gil40254595 & 62638 & 5.95 & 178 & 0.3 & 44 \\
\hline Dynactin subunit 2 & gil51948450 & 44235 & 5.14 & 251 & 0.3 & 50 \\
\hline
\end{tabular}

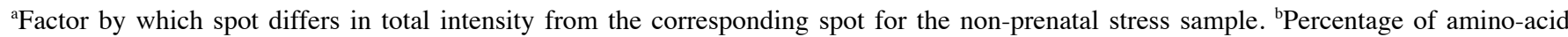
sequence covered by peptides in the MALDI-TOF MS analysis.

the seven polymorphisms i.e., rs4872449, rs431246, rs327222, rs708621 and rs17666.

The haplotype of the polymorphisms within the DPYSL2 gene was evaluated using the Haploview and SNPstats programs. Of the seven SNPs, no LD blocks were constructed using the Gabriel method (38; data not shown). The D' values between the SNPs were $<0.5$, which indicates a very weak LD between each pair of markers. As none of the LD blocks constructed included the three SNPs, a haplotype association study was not performed. The power of the sample size was calculated using a genetic power calculator (http://pngu.mgh. harvard.edu/ purcell/gpc), and the experimental error was reduced by an adjusted effective sample size (calculated sample size $x 100 / 95)$. When the sample power $(\alpha=0.05$, relative risk $=2$, prevalence $=0.02$ ) was estimated, the case-control study was sufficiently powerful to determine a positive association. In this study, it was 0.9144 for rs9886448 (number of cases for $80 \%$ power, $n=143), 0.9161$ for $r 4872449(n=142)$, 
Table VII. Association between frequency of DPYSL2 polymorphisms and schizophrenia.

\begin{tabular}{|c|c|c|c|c|c|c|c|c|c|}
\hline \multirow[b]{2}{*}{ SNP } & \multirow{2}{*}{$\begin{array}{l}\text { Genotype/ } \\
\text { allele }\end{array}$} & \multicolumn{2}{|c|}{ Control } & \multicolumn{2}{|c|}{ Schizophrenia } & \multirow[b]{2}{*}{ Model } & \multirow{2}{*}{$\begin{array}{c}\text { OR } \\
(95 \% \mathrm{CI})\end{array}$} & \multirow[b]{2}{*}{ P-value } & \multirow[b]{2}{*}{ Pc-value } \\
\hline & & $\mathrm{n}$ & $\%$ & $\mathrm{n}$ & $\%$ & & & & \\
\hline rs9886448 & TT & 158 & 49.84 & 122 & 60.4 & Codominant 1 & $0.54(0.36-0.80)$ & 0.003 & 0.02 \\
\hline \multirow[t]{7}{*}{ (promoter-1625T>C) } & $\mathrm{TC}$ & 132 & 41.64 & 55 & 27.2 & Codominant 2 & $1.20(0.66-2.17)$ & & \\
\hline & $\mathrm{CC}$ & 27 & 8.52 & 25 & 12.4 & Dominant & $0.65(0.46-0.93)$ & 0.018 & 0.126 \\
\hline & & & & & & Recessive & $1.52(0.85-2.70)$ & 0.16 & 1 \\
\hline & & & & & & Overdominant & $0.52(0.36-0.77)$ & 0.001 & 0.006 \\
\hline & & & & & & Log-additive & $0.86(0.66-1.12)$ & 0.26 & 1 \\
\hline & $\mathrm{T}$ & 448 & 70.7 & 299 & 74.0 & & & & \\
\hline & $\mathrm{C}$ & 186 & 29.3 & 105 & 26.0 & & $0.846(0.639-1.120)$ & 0.242 & 1 \\
\hline rs4872449 & AA & 149 & 48.85 & 93 & 46 & Codominant 1 & $0.99(0.68-1.44)$ & 0.008 & 0.056 \\
\hline \multirow{7}{*}{$($ promoter-1195A>G) } & $\mathrm{AG}$ & 135 & 44.26 & 83 & 41.1 & Codominant 2 & $1.98(1.06-3.73)$ & & \\
\hline & GG & 21 & 6.89 & 26 & 12.9 & Dominant & $1.12(0.78-1.60)$ & 0.53 & 3.71 \\
\hline & & & & & & Recessive & $2.00(1.09-3.66)$ & 0.024 & 0.168 \\
\hline & & & & & & Overdominant & $0.88(0.61-1.26)$ & 0.48 & 1 \\
\hline & & & & & & Log-additive & $1.23(0.94-1.62)$ & 0.14 & 0.98 \\
\hline & A & 433 & 71.0 & 269 & 66.6 & & & & \\
\hline & $\mathrm{G}$ & 177 & 29.0 & 135 & 33.4 & & $1.228(1.609-0.936)$ & 0.138 & 0.966 \\
\hline rs431246 & $\mathrm{CC}$ & 176 & 55.5 & 117 & 57.9 & Codominant 1 & $0.73(0.49-1.07)$ & 0.011 & 0.077 \\
\hline \multirow[t]{7}{*}{ (promoter-975C>G) } & $\mathrm{CG}$ & 120 & 37.9 & 58 & 28.7 & Codominant 2 & $1.93(1.04-3.58)$ & & \\
\hline & GG & 21 & 6.6 & 27 & 13.4 & Dominant & $0.91(0.63-1.30)$ & 0.59 & 1 \\
\hline & & & & & & Recessive & $2.17(1.19-3.96)$ & 0.011 & 0.077 \\
\hline & & & & & & Overdominant & $0.66(0.45-0.97)$ & 0.031 & 0.217 \\
\hline & & & & & & Log-additive & $1.10(0.85-1.44)$ & 0.47 & 1 \\
\hline & $\mathrm{C}$ & 472 & 74.5 & 292 & 72.3 & & & & \\
\hline & G & 162 & 25.5 & 112 & 27.7 & & $1.118(0.843-1.481)$ & 0.439 & 1 \\
\hline rs2289593 & GG & 236 & 74.45 & 173 & 85.64 & Codominant 1 & $0.48(0.29-0.79)$ & 0.003 & 0.023 \\
\hline \multirow[t]{7}{*}{ (missense $352 \mathrm{G}>\mathrm{A}$ ) } & GA & 72 & 22.71 & 27 & 13.37 & Codominant 2 & $0.29(0.06-1.37)$ & & \\
\hline & AA & 9 & 2.84 & 2 & 0.99 & Dominant & $0.46(0.29-0.74)$ & 0.001 & 0.006 \\
\hline & & & & & & Recessive & $0.33(0.07-1.58)$ & 0.13 & 0.91 \\
\hline & & & & & & Overdominant & $0.49(0.30-0.81)$ & 0.004 & 0.026 \\
\hline & & & & & & Log-additive & $0.49(0.32-0.76)$ & 0.001 & 0.006 \\
\hline & G & 544 & 85.80 & 373 & 92.33 & & & & \\
\hline & $\mathrm{A}$ & 90 & 14.20 & 31 & 7.67 & & $0.502(0.327-0.771)$ & 0.002 & 0.014 \\
\hline rs327222 & $\mathrm{CC}$ & 226 & 71.29 & 151 & 74.75 & Codominant 1 & $0.95(0.63-1.45)$ & 0.073 & 0.511 \\
\hline \multirow[t]{7}{*}{ (synonymous $426 \mathrm{C}>\mathrm{T}$ ) } & CT & 78 & 24.61 & 49 & 24.26 & Codominant 2 & $0.22(0.05-1.00)$ & & \\
\hline & $\mathrm{TT}$ & 13 & 4.10 & 2 & 0.99 & Dominant & $0.84(0.56-1.27)$ & 0.14 & 0.98 \\
\hline & & & & & & Recessive & $0.22(0.05-1.01)$ & 0.023 & 0.161 \\
\hline & & & & & & Overdominant & $0.99(0.66-1.51)$ & 0.98 & 1 \\
\hline & & & & & & Log-additive & $0.78(0.55-1.11)$ & 0.16 & 1 \\
\hline & $\mathrm{C}$ & 530 & 83.60 & 351 & 86.88 & & & & \\
\hline & $\mathrm{T}$ & 104 & 16.40 & 53 & 13.12 & & $0.770(0.538-1.100)$ & 0.151 & 1 \\
\hline rs708621 & $\mathrm{TT}$ & 181 & 57.10 & 112 & 55.45 & Codominant 1 & $1.09(0.74-1.60)$ & 0.86 & 1 \\
\hline \multirow[t]{7}{*}{ (synonymous $1506 \mathrm{~T}>\mathrm{C}$ ) } & $\mathrm{CT}$ & 108 & 34.07 & 74 & 36.63 & Codominant 2 & $0.93(0.48-1.81)$ & & \\
\hline & $\mathrm{CC}$ & 28 & 8.83 & 16 & 7.92 & Dominant & $1.06(0.74-1.52)$ & 0.76 & 1 \\
\hline & & & & & & Recessive & $0.90(0.47-1.72)$ & 0.74 & 1 \\
\hline & & & & & & Overdominant & $1.10(0.76-1.60)$ & 0.61 & 1 \\
\hline & & & & & & Log-additive & $1.01(0.77-1.34)$ & 0.92 & 1 \\
\hline & $\mathrm{C}$ & 470 & 74.13 & 298 & 73.76 & & & & \\
\hline & $\mathrm{T}$ & 164 & 25.87 & 106 & 26.24 & & $1.019(0.767-1.354)$ & 0.895 & 1 \\
\hline rs17666 & $\mathrm{TT}$ & 234 & 73.8 & 161 & 79.7 & Codominant 1 & $0.81(0.52-1.25)$ & 0.03 & 0.21 \\
\hline \multirow[t]{7}{*}{$(3 ' \mathrm{UTR} * 2236 \mathrm{~T}>\mathrm{C})$} & $\mathrm{TC}$ & 72 & 22.7 & 40 & 19.8 & Codominant 2 & $0.13(0.02-1.03)$ & & \\
\hline & $\mathrm{CC}$ & 11 & 3.5 & 1 & 0.5 & Dominant & $0.72(0.47-1.10)$ & 0.12 & 0.84 \\
\hline & & & & & & Recessive & $0.14(0.02-1.08)$ & 0.015 & 0.105 \\
\hline & & & & & & Overdominant & $0.85(0.55-1.32)$ & 0.48 & 1 \\
\hline & & & & & & Log-additive & $0.68(0.47-1.01)$ & 0.049 & 0.343 \\
\hline & $\mathrm{T}$ & 540 & 85.1 & 362 & 89.6 & & & & \\
\hline & $\mathrm{C}$ & 94 & 14.9 & 42 & 10.4 & & $0.667(0.452-0.982)$ & 0.04 & 0.28 \\
\hline
\end{tabular}

OR, odds ratio; CI, confidence interval; Pc-value, Bonferroni corrected P-value. DPYSL2, dihydropyrimidinase-like 2. 
0.9323 for $\mathrm{rs} 431246(\mathrm{n}=132), 0.9387$ for $\mathrm{rs} 2289593(\mathrm{n}=129)$, 0.944 for $\mathrm{rs} 327222(\mathrm{n}=125), 0.9308$ for $\mathrm{rs} 708621(\mathrm{n}=133)$, and 0.9409 for $\operatorname{rs} 17666(\mathrm{n}=127)$.

Promoter activity of SNPs located in the promoter region. We investigated whether the two promoter SNPs (rs9886448 and rs 4872449) altered the transcriptional activity of the DPYSL2 promoter sequence. The results of an in silico promoter-binding prediction algorithm (http://www.generegulation.com/pub/programs/alibaba2) suggested that SNPs may not affect DPYSL2 gene transcription (data not shown) and, thus, their effects on promoter activity in human SH-SY5Y neuroblastoma cells was examined in vitro. To assess the promoter activity of the SNPs, plasmids containing one allele from each SNP and a luciferase reporter gene were transfected into human SH-SY5Y neuroblastoma cells, and the reporter activities of the four constructs of the two SNPs were compared. No significant differences in luciferase activity was observed in any of the pGL3 basic constructs with alleles of the SNPs (relative promoter activity in percentage): rs 9886448 ; pGL3-allele/pRL-SV40, pGL3-basic, $100.00 \pm 37 \%$; TT, $57.92 \pm 22 \%$; CC, $74.21 \pm 25 \%$; and rs 4872449 ; pGL3-basic, $100.00 \pm 19 \%$; AA, $104.61 \pm 35 \%$; GG, $93.82 \pm 28 \%$.

\section{Discussion}

The present study investigated a novel target, DPYSL2, to examine the pathophysiology of schizophrenia using proteomic analyses in a PNS animal model associated with the neurodevelopmental theory of schizophrenia.

Dpys12, also known as collapsin response mediator protein 2 (Crmp2), was first identified in chick dorsal root ganglia cultures as a signal transducer responsible for axon growth cone retraction induced by negative guidance signals from the semaphorin 3A (Sema3A) pathway of the developing nervous system (37). Dpysl2 is a multifunctional adaptor protein in the central nervous system that uses a cytosolic protein as the primary sequence homology to the dihydropyrimidinase enzyme (DPYS) responsible for uracil and thymine catabolism (39). In the developing brain, Dpysl2 regulates axonal outgrowth via the promotion of microtubule assembly, vesicle trafficking, and synaptic physiology (15,31-43). In experiments investigating Dpysl2 and its derivatives, only the C-terminal region mediates microtubule binding, and Dpysl2-depleted cells exhibit destabilized anaphase astral microtubules and altered spindle positions.

An 82-residue C-terminal region of Dpys12, unrelated to other microtubule binding motifs, is sufficient to stabilize microtubules (41), and Dpysl2 has been shown to be involved in the regulation of neurite outgrowth in the neurite shaft and growth cone (42). Dpysl2 binds directly to $\mathrm{N}$-type $\mathrm{Ca}^{2+}(\mathrm{CaV} 2.2)$ channels in two regions: the channel domain I-II intracellular loop and the distal C terminus (43). Overexpression of the Dpysl2 protein in hippocampal neurons causes an increase in $\mathrm{Ca}^{2+}$ channel present density whereas a lentivirus-mediated Dpysl2 knockdown eliminates this effect (43). The study also revealed an increased number of $\mathrm{CaV} 2.2$ channels on the cell surface of Dpysl2-overexpressing neurons, which also show a significant increase in vesicular release in response to a depolarizing stimulus. The depolar- ization of Dpysl2-overexpressing neurons elicits an increase in the release of glutamate (43), and dysfunction within the Dpys12 system may result in neurodevelopmental abnormalities, such as unregulated axonal growth and branching, which may be a factor into the pathogenesis of schizophrenia. The expression of DPYSL2 in humans has been reported to be decreased in the brains of patients with schizophrenia (44). Additionally, DPYSL2 is located on chromosome 8p21, a region that has been associated with schizophrenia in genetic linkage studies (45).

The present findings suggest that application of a repeated variable PNS paradigm during the critical periods of fetal brain development results in Dpysl2 protein expression changes that may have enduring effects on axonal outgrowth and synaptic function in the offspring during adulthood. Taken together with functional positional evidence, the present experimental results indicate that mutations or polymorphisms in and/or nearby the DPYSL2 gene may play a role in genetic susceptibility for and development of schizophrenia. Thus, the association between the functional SNPs of DPYSL2 and schizophrenia was examined. The present findings demonstrated that SNPs in the promoter (rs9886448) and exon (rs2289593) regions were associated with susceptibility for schizophrenia. Polymorphisms of the promoter SNP (rs9886448) did not affect the promoter activity of the sequence around the SNP. However, the functional alterations that may have been induced by these polymorphisms (rs2289593) have not been evaluated, which is a limitation of this study,

The genotype frequencies for SNPs in Korean, European, Chinese, Japanese, and Sub-Saharan African populations were compared to confirm the present genotyping data (Table VIII). The rs9886448, rs4872449, rs2289539 and rs708621 genotype distributions in the present control Korean group were generally similar to those of the Chinese and Japanese populations. However, the A/G genotype of rs 2289539 has not been detected in any population, although the $\mathrm{A} / \mathrm{G}$ genotype in the present population was detected at high frequencies. The rs327222 genotype distribution was similar to the Sub-Saharan African distribution and the rs17666 genotype distribution was similar to the European distribution. However, the genotype distributions of the European, Chinese, Japanese and Sub-Saharan African populations were generally not similar to that of the present schizophrenia group. Therefore, the genotypic differences among ethnic groups may be derived from the ethnicity of each population, and the genotype distributions of the present schizophrenia group may have been associated with the disease condition. These comparisons suggest that the present genotyping results are reliable for genetic association studies as most of the distributions were similar to the Asian population albeit not to the European and Sub-Saharan African populations.

Additionally, the candidate gene sequences from humans were compared with those of mice to identify a direct relationship between the human DPYSL2 gene and polymorphisms in mice (data not shown). The mRNA sequence of the gene was very similar across species (http://blast.ncbi.nlm.nih.gov); the maximum identity of the gene was $87 \%$, and the transcript sequences of the human gene were very similar to those of mice. However, the exonic SNP of the human gene was not identified in rat sequences. Although the site is the same in 
Table VIII. Genotype frequencies of DPYSL2 SNPs in various populations (www.ncbi.nlm.nih.gov/SNP, dbSNP Build 139).

\begin{tabular}{|c|c|c|c|c|c|c|c|}
\hline \multirow[b]{2}{*}{ SNP } & \multirow[b]{2}{*}{ Genotype/allele } & \multicolumn{2}{|c|}{ Korean } & \multirow[b]{2}{*}{ European } & \multirow[b]{2}{*}{ Chinese } & \multirow[b]{2}{*}{ Japanese } & \multirow[b]{2}{*}{ Sub-Saharan African } \\
\hline & & Schizophrenia & Control & & & & \\
\hline \multirow[t]{5}{*}{ rs9886448 } & $\mathrm{C} / \mathrm{C}$ & 0.085 & 0.124 & 0.018 & 0.047 & 0.07 & 0.035 \\
\hline & $\mathrm{C} / \mathrm{T}$ & 0.416 & 0.272 & 0.15 & 0.326 & 0.384 & 0.292 \\
\hline & $\mathrm{T} / \mathrm{T}$ & 0.498 & 0.604 & 0.832 & 0.628 & 0.547 & 0.673 \\
\hline & $\mathrm{C}$ & 0.26 & 0.293 & 0.093 & 0.209 & 0.262 & 0.181 \\
\hline & $\mathrm{T}$ & 0.74 & 0.707 & 0.907 & 0.791 & 0.738 & 0.819 \\
\hline \multirow[t]{5}{*}{ rs4872449 } & $\mathrm{A} / \mathrm{A}$ & 0.46 & 0.489 & 0.203 & 0.4 & 0.432 & 0 \\
\hline & $\mathrm{A} / \mathrm{G}$ & 0.411 & 0.443 & 0.508 & 0.489 & 0.409 & 0 \\
\hline & $\mathrm{G} / \mathrm{G}$ & 0.129 & 0.069 & 0.288 & 0.111 & 0.159 & 1 \\
\hline & A & 0.666 & 0.71 & 0.458 & 0.664 & 0.636 & 0 \\
\hline & G & 0.334 & 0.29 & 0.542 & 0.356 & 0.364 & 1 \\
\hline \multirow[t]{5}{*}{ rs2228979 } & $\mathrm{A} / \mathrm{A}$ & 0.01 & 0.028 & 0 & 0.133 & 0.114 & 0 \\
\hline & $\mathrm{A} / \mathrm{G}$ & 0.134 & 0.227 & 0 & 0 & 0 & 0 \\
\hline & $\mathrm{G} / \mathrm{G}$ & 0.856 & 0.745 & 1 & 0.867 & 0.886 & 1 \\
\hline & A & 0.077 & 0.142 & 0 & 0.067 & 0.057 & 0 \\
\hline & G & 0.923 & 0.858 & 1 & 0.933 & 0.943 & 1 \\
\hline \multirow[t]{5}{*}{ rs327222 } & $\mathrm{C} / \mathrm{C}$ & 0.748 & 0.713 & 0.991 & 0.814 & 0.895 & 0.761 \\
\hline & $\mathrm{C} / \mathrm{T}$ & 0.243 & 0.246 & 0.009 & 0.186 & 0.105 & 0.221 \\
\hline & $\mathrm{T} / \mathrm{T}$ & 0.01 & 0.041 & 0 & 0 & 0 & 0.018 \\
\hline & $\mathrm{C}$ & 0.869 & 0.836 & 0.996 & 0.907 & 0.948 & 0.872 \\
\hline & $\mathrm{T}$ & 0.131 & 0.164 & 0.004 & 0.093 & 0.052 & 0.128 \\
\hline \multirow[t]{5}{*}{ rs708621 } & $\mathrm{C} / \mathrm{C}$ & 0.079 & 0.088 & 0.55 & 0.113 & 0.133 & 0.65 \\
\hline & $\mathrm{C} / \mathrm{T}$ & 0.366 & 0.341 & 0.367 & 0.556 & 0.378 & 0.3 \\
\hline & $\mathrm{T} / \mathrm{T}$ & 0.555 & 0.571 & 0.083 & 0.311 & 0.489 & 0.05 \\
\hline & $\mathrm{C}$ & 0.738 & 0.741 & 0.773 & 0.411 & 0.322 & 0.8 \\
\hline & $\mathrm{T}$ & 0.262 & 0.259 & 0.267 & 0.589 & 0.678 & 0.2 \\
\hline \multirow[t]{5}{*}{ rs17666 } & $\mathrm{C} / \mathrm{C}$ & 0.005 & 0.035 & 0.023 & 0.012 & 0.239 & 0.306 \\
\hline & $\mathrm{C} / \mathrm{T}$ & 0.198 & 0.227 & 0.279 & 0.314 & 0.451 & 0.449 \\
\hline & $\mathrm{T} / \mathrm{T}$ & 0.797 & 0.738 & 0.689 & 0.674 & 0.31 & 0.245 \\
\hline & $\mathrm{C}$ & 0.104 & 0.149 & 0.163 & 0.169 & 0.465 & 0.531 \\
\hline & $\mathrm{T}$ & 0.896 & 0.851 & 0.837 & 0.831 & 0.535 & 0.469 \\
\hline
\end{tabular}

DPYSL2, dihydropyrimidinase-like 2; SNP, single nucleotide polymorphism.

the two species, it is not polymorphic in the rat. A polymorphism of the human DPYSL2 gene located in the promoter region (rs9886448) was not identified in the rat sequences as the promoter region of human and mouse sequences differ. Therefore, none of the polymorphisms of the human DPYSL2 was identified in the rat genome, which is another limitation of the present study.

In this study, DPYSL2 was shown to be affected by the PNS paradigm and was associated with the neurodevelopmental theory of schizophrenia. PNS during gestation is involved in the pathology of various psychiatric disorders, such as schizophrenia and depression, and constitutes a pathogenetic theory. Based on gel-based proteomic and genetic population studies, PNS during the critical periods of fetal brain development can result in clearly altered expression patterns of Dpysl2. The upstream and missense SNPs of the PNS-associated gene DPYSL2 exhibit clear alterations in genetic studies of human patients with schizophrenia. These results suggest that DPYSL2 is likely associated with susceptibility to schizophrenia in humans, which is consistent with the association of Dpys12 changes in the rat model of PNS.

In conclusion, the neurodevelopmental theory of schizophrenia and susceptibility to schizophrenia appear to connect the DPYSL2 gene with the disease as the present results suggest DPYSL2 and its SNPs in the pathophysiology of schizophrenia. To the best of our knowledge, this is not the first study to identify a relationship between the DPYSL2 gene and schizophrenia, but it is the first to investigate this relationship in terms of the neurodevelopmental theory of schizophrenia. Additionally, this study investigates the correlation in a Korean population. Therefore, the present study provides valuable data regarding pathogenesis of psychiatric disorders such as schizophrenia. 
However, studies using cellular or animal model systems are required to elucidate the actual role of DPYSL2.

\section{Acknowledgements}

The study was supported by the Basic Science Research Program of the National Research Foundation of Korea funded by the Ministry of Education, Science and Technology (2010-0021521) and the Soonchunhyang University Research Fund. We thank all involved investigators and study patients in this study.

\section{References}

1. Ross CA, Margolis RL, Reading SA, et al: Neurobiology of schizophrenia. Neuron 52: 139-153, 2006.

2. Lewis DA and Lieberman JA: Catching up on schizophrenia: natural history and neurobiology. Neuron 28: 325-334, 2000.

3. Brown AS, van Os J, Driessens C, et al: Further evidence of relation between prenatal famine and major affective disorder. Am J Psychiatry 157: 190-195, 2000.

4. Sullivan PF: The genetics of schizophrenia. PLoS Med 2: e212, 2005.

5. Huttunen MO and Niskanen P: Prenatal loss of father and psychiatric disorder. Arch Gen Psychiatry 35: 429-431, 1978.

6. King M, Nazroo J, Weich S, et al: Psychotic symptoms in the general population of England - a comparison of ethnic groups (The EMPIRIC study). Soc Psychiatry Psychiatr Epidemiol 40: 375-381, 2005.

7. King S, Laplante D and Joober R: Understanding putative risk factors for schizophrenia: retrospective and prospective studies. J Psychiatry Neurosci 30: 342-348, 2005.

8. Lim C, Chong SA and Keefe R: Psychosocial factors in the neurobiology of schizophrenia: a selective review. Ann Acad Med Singapore 38: 402-406, 2009.

9. Imamura Y, Nakane Y, Ohta Y and Kondo H: Lifetime prevalence of schizophrenia among individuals prenatally exposed to atomic bomb radiation in Nagasaki City. Acta Psychiatr Scand 100: 344-349, 1999.

10. Meyer U and Feldon J: Epidemiology-driven neurodevelopmental animal models of schizophrenia. Prog Neurobiol 90: 285-326, 2010.

11. Weinstock M: The long-term behavioural consequences of prenatal stress. Neurosci Biobehav Rev 32: 1073-1086, 2008.

12. Seckl JR: Prenatal glucocorticoids and long-term programming. Eur J Endocrinol 151 (Suppl 3): U49-U62, 2004.

13. de Kloet ER, Sibug RM, Helmerhorst FM and Schmidt MV: Stress, genes and the mechanism of programming the brain for later life. Neurosci Biobehav Rev 29: 271-281, 2005.

14. Beydoun H and Saftlas AF: Physical and mental health outcomes of prenatal maternal stress in human and animal studies: a review of recent evidence. Paediatr Perinat Epidemiol 22: 438-466, 2008

15. Lee PR, Brady DL, Shapiro RA, et al: Prenatal stress generates deficits in rat social behavior: Reversal by oxytocin. Brain Res 1156: 152-167, 2007.

16. Kinnunen AK, Koenig JI and Bilbe G: Repeated variable prenatal stress alters pre- and postsynaptic gene expression in the rat frontal pole. J Neurochem 86: 736-748, 2003.

17. Koenig JI, Elmer GI, Shepard PD, et al: Prenatal exposure to a repeated variable stress paradigm elicits behavioral and neuroendocrinological changes in the adult offspring: potential relevance to schizophrenia. Behav Brain Res 156: 251-261, 2005.

18. Koenig JI, Elmer GI, Shepard PD, et al: Stress during gestation produces alterations in adult rat behavior: relevance to schizophrenia. Soc Neurosci Abstr: 495-496, 2002

19. Lordi B, Protais P, Mellier D and Caston J: Acute stress in pregnant rats: effects on growth rate, learning, and memory capabilities of the offspring. Physiol Behav 62: 1087-1092, 1997.

20. Vallée M, MacCari S, Dellu F, et al: Long-term effects of prenatal stress and postnatal handling on age-related glucocorticoid secretion and cognitive performance: a longitudinal study in the rat. Eur J Neurosci 11: 2906-2016, 1999.

21. Szuran TF, Pliska V, Pokorny J and Welzl H: Prenatal stress in rats: effects on plasma corticosterone, hippocampal glucocorticoid receptors, and maze performance. Physiol Behav 71: $353-362,2000$
22. Nishio H, Kasuga S, Ushijima M and Harada Y: Prenatal stress and postnatal development of neonatal rats-sex-dependent effects on emotional behavior and learning ability of neonatal rats. Int J Dev Neurosci 19: 37-45, 2001.

23. Walder DJ, Walker EF and Lewine RJ: Cognitive functioning, cortisol release, and symptom severity in patients with schizophrenia. Biol Psychiatry 48: 1121-1132, 2000.

24. Kuperberg G and Heckers S: Schizophrenia and cognitive function. Curr Opin Neurobiol 10: 205-210, 2000.

25. Hayashi A, Nagaoka M, Yamada K, et al: Maternal stress induces synaptic loss and developmental disabilities of offspring. Int J Dev Neurosci 16: 209-216, 1998.

26. Lemaire V, Koehl M, Le Moal M and Abrous DN: Prenatal stress produces learning deficits associated with an inhibition of neurogenesis in the hippocampus. Proc Natl Acad Sci USA 97: 11032-11037, 2000.

27. Martínez-Téllez RI, Hernández-Torres E, Gamboa C and Flores G: Prenatal stress alters spine density and dendritic length of nucleus accumbens and hippocampus neurons in rat offspring. Synapse 63: 794-804, 2009.

28. Van den Hove DL, Kenis G, Brass A, et al: Vulnerability versus resilience to prenatal stress in male and female rats; implications from gene expression profiles in the hippocampus and frontal cortex. Eur Neuropsychopharmacol 23: 1226-1246, 2013.

29. Mairesse J, Vercoutter-Edouart AS, Marrocco J, et al: Proteomic characterization in the hippocampus of prenatally stressed rats. J Proteomics 75: 1764-1770, 2012.

30. Dulawa SC, Holick KA, Gundersen B and Hen R: Effects of chronic fluoxetine in animal models of anxiety and depression. Neuropsychopharmacology 29: 1321-1330, 2004

31. Schroeder M, Sultany T and Weller A: Prenatal stress effects on emotion regulation differ by genotype and sex in prepubertal rats. Dev Psychobiol 55: 176-192, 2013.

32. Becker A, Peters B, Schroeder H, et al: Ketamine-induced changes in rat behaviour: A possible animal model of schizophrenia. Prog Neuropsychopharmacol Biol Psychiatry 27: 687-700, 2003.

33. Joo J, Lee S, Nah SS, et al: Lasp1 is down-regulated in NMDA receptor antagonist-treated mice and implicated in human schizophrenia susceptibility. J Psychiatr Res 47: 105-112, 2013.

34. American Psychiatric Association: Diagnostic and Statistical Manual of Mental Disorders. 4th edition, American Psychiatric Press, Washington, p886, 1994.

35. Nakata K, Ujike H, Sakai A, et al: The human dihydropyrimidinaserelated protein 2 gene on chromosome $8 \mathrm{p} 21$ is associated with paranoid-type schizophrenia. Biol Psychiatry 53: 571-576, 2003.

36. Lee BK, Lee SJ, Joo JS, et al: Association of Glutathione S-transferase genes (GSTM1 and GSTT1) polymorphisms with hypertension in lead-exposed workers. Mol Cell Toxicol 8: 203-208, 2012

37. Goshima Y, Nakamura F, Strittmatter P and Strittmatter SM: Collapsin-induced growth cone collapse mediated by an intracellular protein related to UNC-33. Nature 376: 509-514, 1995.

38. Gabriel SB, Schaffner SF, Nguyen H, et al: The structure of haplotype blocks in the human genome. Science 296: 2225-2229, 2002.

39. Arai $\mathbf{M}$ and Itokawa $\mathrm{M}$ : A hard road in psychiatric genetics: schizophrenia and DPYSL2. J Hum Genet 55: 397-399, 2010.

40. Arimura N, Menager C, Fukata Y and Kaibuchi K: Role of CRMP-2 in neuronal polarity. J Neurobiol 58: 34-47, 2004.

41. Lin PC, Chan PM, Hall C and Manser E: Collapsin response mediator proteins (CRMPs) are a new class of microtubule-associated protein (MAP) that selectively interacts with assembled microtubules via a taxol-sensitive binding interaction. J Biol Chem 286: 41466-41478, 2011.

42. Higurashi M, Iketani M, Takei K, et al: Localized role of CRMP1 and CRMP2 in neurite outgrowth and growth cone steering. Dev Neurobiol 72: 1528-1540, 2012.

43. Brittain JM, Piekarz AD, Wang Y, et al: An atypical role for collapsin response mediator protein 2 (CRMP-2) in neurotransmitter release via interaction with presynaptic voltage-gated calcium channels. J Biol Chem 284: 31375-31390, 2009.

44. Johnston-Wilson NL, Sims CD,Hofmann JP, et al: Disease-specific alterations in frontal cortex brain proteins in schizophrenia, bipolar disorder, and major depressive disorder. The Stanley Neuropathology Consortium. Mol Psychiatry 5: 142-149, 2000.

45. Fallin MD, Lasseter VK, Liu Y, et al: Linkage and association on 8p21.2-p21.1 in schizophrenia. Am J Med Genet B Neuropsychiatr Genet 156: 188-197, 2011. 